九州大学学術情報リポジトリ

Kyushu University Institutional Repository

\title{
The Exergy Investigation of a Mechanical Vapor Compression Chiller for Cooling Using R410a
}

\section{Uthpala Perera}

Interdisciplinary Graduate School of Engineering Sciences, Kyushu University

Takata, Nobuo

Interdisciplinary Graduate School of Engineering Sciences, Kyushu University

Miyazaki, Takahiko

Interdisciplinary Graduate School of Engineering Sciences, Kyushu University

Higashi, Yukihiro

Research Center for Next Generation Refrigerant Properties (NEXT-RP), I2CNER-WPI, Kyushu University

他

https://doi.org/10.5109/4372281

出版情報 : Evergreen. 8 (1)，pp.213-220，2021-03. 九州大学グリーンテクノロジー研究教育センター バージョン：

権利関係 : 


\title{
The Exergy Investigation of a Mechanical Vapor Compression Chiller for Cooling Using R410a
}

\author{
Uthpala Perera $^{1, *}$, Nobuo Takata ${ }^{1}$, Takahiko Miyazaki ${ }^{1,2}$, Yukihiro Higashi ${ }^{2}$ and \\ Kyaw $\mathrm{Thu}^{1,2}$ \\ ${ }^{1}$ Interdisciplinary Graduate School of Engineering Sciences, Kyushu University, Japan \\ ${ }^{2}$ Research Center for Next Generation Refrigerant Properties (NEXT-RP), I²CNER-WPI, Kyushu University, \\ Japan
}

*Author to whom correspondence should be addressed: E-mail: perera.c.845@s.kyushu-u.ac.jp

(Received November 23, 2020; Revised March 25, 2021; accepted March 26, 2021).

\begin{abstract}
R410a will remain a common refrigerant in developing nations, even though its high environmental impact assures its eventual phase out. In the hopes of tackling the afore mentioned and identifying potential areas of improvement, the performance of a $2.0 \mathrm{~kW}$ chiller is evaluated. The first law of thermodynamics highlights the disadvantage of overcharging the refrigerant amount and the second law applied through an exergy approach points to the compressor as the largest contributor to exergy destroyed and its effects on reducing condenser performance as well. This analysis can be directly compared with alternative refrigerants to replace R410a in the future.
\end{abstract}

Keywords: Exergy; Chiller; R410a

\section{Introduction}

The need for cooling has been increasing ${ }^{1)}$ since the introduction of the commercial air conditioner in the early $1900 \mathrm{~s}^{2}$. A report by the International Energy Agency (IEA) shows that the increase in demand for cooling will result in a threefold increase in global energy use for cooling compared to the 2016 level $^{3}$. The main drivers of this increase are the increased global temperatures resulting from global warming and climate change ${ }^{4)}$ which have led to frequent unbearable heat waves through many countries, the increase in living standards of people especially in developing nations and the creation of urban heat island effects due to the rise in urbanization. Unsurprisingly, the largest contributors to the increased growth of the cooling industry is seen in Asia, with China, India and Indonesia collectively resulting in half of the projected cooling energy use in $2050^{3)}$.

This anticipated increase in demand has led to many studies involving cooling technologies. Mahmood et al. ${ }^{5}$ have presented work on using water based adsorbents for producing air conditioning and also gone on to explore the possibility of using desiccants for the commercial food chain, specifically for storing fruits and vegetables ${ }^{6}$. Similarly, Yaningsih et al. ${ }^{7)}$ have focused on using alternative desiccant systems for providing dehumidification which is a key part in air conditioning applications. Byrne et al. ${ }^{8)}$ have proposed a vapor compression system for large scale applications to a resort which utilizes the variable energy supply from solar power and thermal storage to overcome the use of batteries and the intermittent nature of solar power. Ali et al. ${ }^{9}$ have even gone onto analyze the possibility of using adsorption systems for automotive applications and Ko et al. ${ }^{10)}$ have presented the possibilities of focusing on $5 \mathrm{G}$ technology and using real time data for optimizing cooling systems. These studies collectively show the innovation within the cooling industry.

As mentioned above, there have been many developments and research carried out in all fields of cooling. However, when the cooling demand is broken down into the commercial and residential sectors, it is clear that the largest contribution is caused by the latter, in both the number of units and the overall energy consumption $^{3)}$. A further look at the breakdown of the particular types of cooling systems used reveals that minisplit types and multi-split type air conditioners occupy around $77 \%$ of the market ${ }^{3}$. These split type units which work on the mechanical vapor compression (MVC) cycle have often been using R410a as the main refrigerant since moving away from R22 ${ }^{11)}$ which possessed high ozone depletion potential $(O D P)$. Many countries including the European Union ${ }^{12,13)}$, Japan ${ }^{14,15)}$ and several other nations ${ }^{16)}$ which fall under the Group $5^{17)}$ of the Montreal Protoco ${ }^{18)}$, still rely on R410a even with the phase out of this refrigerant eminent under the Kigali Amendment ${ }^{19}$. The use of R410a is currently being controlled by the Kigali Amendment and several other fluorine gas 
regulations $^{20,21)}$ across the globe due to its high global warming potential (GWP). However, since many countries are either still in the transition phase or have several years remaining till the strict control of R410a occurs, there is a necessity to explore alternatives to this high GWP refrigerant and also to continue improving the performance of R410a based systems.

Several key studies related to the use of R410a have already been published by Fukuda et al. ${ }^{22,23)}$ and Thu et al. ${ }^{24)}$ have focused on the heating applications which are of importance to countries at higher latitudes. Chen W. ${ }^{25}$ ) has used simulations to compare the performance and environmental impact of converting residential air conditioners larger than $3.0 \mathrm{~kW}$ to R410a from R22. Fukuda et al. ${ }^{26)}$ has also looked at the cooling applications of R410a with respect to the cycle performance, by using the internal measurements of the refrigerant side properties. This method is often more applicable to scientific studies rather than practical and industrial evaluations. The authors have also have studied the cooling conditions as per the air conditioning, heating and refrigeration institute (AHRI) standards and also explored the exergy analysis of the system which was limited to 1.6 $\mathrm{kW}$ of cooling ${ }^{27}$.

Beyond simple performance evaluations, the use of exergy analysis has been proven to be important in finding the key areas of improvement for a chiller or other complicated systems such as coal fire plants ${ }^{28}$. Exergy analysis involves not just the quantity of energy, but also the quality of that energy. The exergy analysis can point out the locations at which irreversibilities or losses occur and the quality of work is decreased. This form of analysis is crucial in improving the utilization of energy within each component and the overall system. Exergy analysis allows the determination of how effectively the energy available is being utilized by a system. This would help in increasing the effectiveness in overall consumption of natural resources such as fossil fuels for electricity production or in the case of a chiller, the use of electricity for producing cooling. For a chiller, a similar analysis has been presented in the authors' previous work ${ }^{27)}$, but was limited to a capacity of $1.6 \mathrm{~kW}$ of cooling and the charge amount of $0.80 \mathrm{~kg}$. As highlighted by Jemma et al. ${ }^{29)}$ when comparing the two refrigerants R134a and R1234ze, the compressor contributed to the largest exergy destruction, which was also presented in the author's previous conclusions. The effects of varying the evaporator and condenser temperatures have been explored by Yumrutas et al. $^{30)}$ where narrowing the temperature difference between the refrigerant and external states helped reduce the exergy destruction and also improve the exergy efficiency. For the case of an automotive air conditioner, Cho et al. ${ }^{31)}$ pointed out how the compressor speed would change the ratio of exergy destruction between the compressor and other components when using an internal heat exchanger for the two refrigerants R134a and R1234yf. The limits of improvement which can be achieved for components and even the system have been also shown under studies by Morusuk et al. ${ }^{32)}$ where the possible improvements to reducing the exergy destroyed or increasing the exergy efficiency can be achieved by reducing irreversible losses within the components, but are said to be limited by the technology or the intrinsic nature of the processes. They also point out that there is an effect on the exergy destruction caused by one component, on the exergy destruction within another component as well. Other studies have shown that exergy analysis can even be applied to simulations and is not limited to experimental work as seen in research by Bilgen et al. ${ }^{33)}$ and Alhamid et al. ${ }^{34)}$.

However, for the case of small capacity split units which often caters to a single room, the system analysis for R410a under regular operating conditions has not been carried out. Using an exergy analysis method similar to those mentioned before would allow an in-depth look into the occurrences of irreversibilities within each component and also explore the inter-component effects on performance based on exergy destruction. Thus a $2 \mathrm{~kW}$ chiller is operated at varied cooling capacities and variable charge amounts to determine its performance characteristics and also evaluate its exergetic performance. The external circuit or water side properties and power consumption are used in order to easily measure the performance of the system as a whole, whilst more indepth analysis has employed internal measurements to provide a more holistic evaluation. Utilizing the first law of thermodynamics the basic performance is analyzed and then the second law of thermodynamics is employed for a look into the exergy destruction at the component level as well as the system exergetic efficiency, which are all presented herein, together with the exergy defect and specific exergy defect which focus on inter-component effects.

\section{Experimental methodology}

\subsection{Experimental apparatus}

The experimental apparatus is a $2 \mathrm{~kW}$ rated chiller with variable speed compressor and chilled water and cooling water systems (see Fig. 1). This apparatus has been previously described in literature ${ }^{24,27)}$. The inverter power to the compressor can be recorded, whilst the temperatures and pressures at the inlets and outlets of the heat exchangers both in the water side and refrigerant side, as well as the suction and discharge points of the compressor and inlet and outlet of the expansion device together with the mass flow rates are recorded. The required conditions for the cooling mode are shown in Table 1. Under these conditions the cooling capacity can be varied between 1.4 $\mathrm{kW}$ and $2.4 \mathrm{~kW}$, whilst the R410a charge amount is varied between $0.74 \mathrm{~kg}$ and $0.90 \mathrm{~kg}$. 


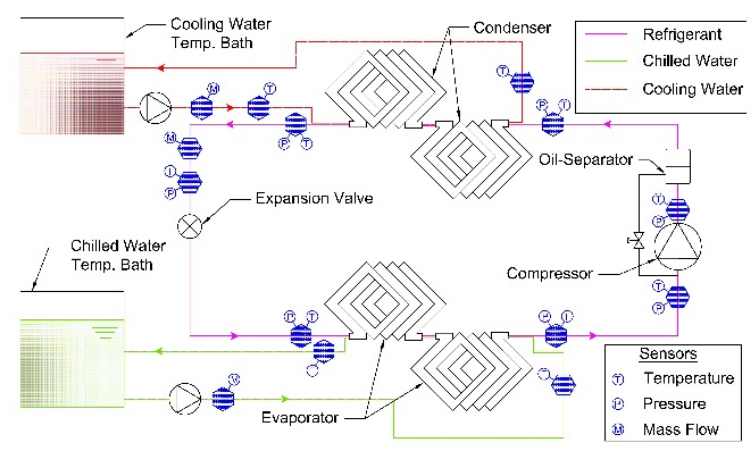

Fig. 1: The schematic of the mechanical vapor compression chiller.

Table 1. Experimental conditions for the chiller.

\begin{tabular}{|l|c|c|}
\hline Parameters & Inlet & Outlet \\
\hline $\begin{array}{l}\text { Evaporator chilled water temperature } \\
\left({ }^{\circ} \mathrm{C}\right)\end{array}$ & 20 & 10 \\
\hline $\begin{array}{l}\text { Condenser cooling water temperature } \\
\left({ }^{\circ} \mathrm{C}\right)\end{array}$ & 30 & 45 \\
\hline Superheat $(\mathrm{K})$ & \multicolumn{2}{|c|}{$4 \pm 1$} \\
\hline
\end{tabular}

\subsection{Equations}

The analysis of the MVC cycle is carried out based on the first and second laws of thermodynamics. The refrigerant properties when required are determined using Refprop $10.0^{35)}$ and the analysis of data has been carried out using Mathematica ${ }^{36)}$ software. Utilizing the first law, the energy balance $(E B)$ is first calculated to ascertain the validity of the results to follow. This is carried out in a similar method as presented in previous works ${ }^{27,37)}$. The energy balance as shown in Eq. 1, should be equal to 1 in the ideal case, but takes an acceptable average value of 0.04 which is within $4 \%$ and thus representing the validity in both the measurements carried out, as well as the further calculations on properties such as heat transfer.

$$
E B=\frac{\dot{Q}_{\text {Evap }}+P_{\text {Comp }}-\dot{Q}_{\text {Cond }}}{\dot{Q}_{\text {Cond }}}
$$

Secondly the basic indicator of performance for a chiller, the coefficient of performance (COP) of the system is determined based on Eq. 2, where the cooling effect of the chiller is measured using the chilled water side properties, whilst the power input into the system is directly read off the power meter of the compressor. The employment of external measurements provides an easy way to compare this performance with other chillers and even other refrigerants, which is essential in the case of R410a which should be phased out of use in the near future as per international treaties and local laws in many countries.

$$
\mathrm{COP}=\frac{\dot{m}_{C H} \times c_{p} \times\left(T_{C H, I n}-T_{C H, \text { Out }}\right)}{P_{\text {Comp }}}
$$

Moving on to the second law analysis, the exergy destruction is calculated based on the dead state temperature and pressure of $T_{0}=298.15 \mathrm{~K}$ and $P_{0}=$ $101.325 \mathrm{kPa}$. The general form of the exergy destruction equation applied is shown in Eq. 3 - 4, whilst more detailed expressions for each component of the cycle is provided from Eq. $5-8$ as referred to in previously published work ${ }^{27,37)}$.

$$
\begin{aligned}
& \dot{E}_{D}=\sum_{j=1}^{n}\left(1-\frac{T_{o}}{T_{j}}\right) \dot{Q}_{j}+\left(\dot{W}_{c v}+p_{o} \frac{d V_{c v}}{d t}\right)+\sum_{i} \dot{m}_{i} e_{f i}-\sum_{e} \dot{m}_{e} e_{f e}, \\
& e_{f}=\left(h_{i}-h_{0}\right)-T_{0}\left(s_{i}-s_{0}\right) \\
& \dot{E}_{D, \text { Evap }}=\dot{m}_{\text {ref }}\left(e_{f, \text { Evap }, \text { In }}-e_{f, \text { Evap }, \text { Out }}\right)+\dot{m}_{C H}\left(e_{f, C H, I n}-e_{f, \text { CH, Out }}\right), \\
& \dot{E}_{D, \text { Cond }}=\dot{m}_{\text {ref }}\left(e_{f, \text { Cond }, \text { In }}-e_{f, \text { Cond }, \text { Out }}\right)+\dot{m}_{C W}\left(e_{f, C W, \text { In }}-e_{f, C W, \text { Out }}\right), \\
& \dot{E}_{D, \text { Comp }}=W_{\text {Comp }}+\dot{m}_{\text {ref }}\left(e_{f, \text { Comp }, \text { In }}-e_{f, \text { Comp }, \text { Out }}\right), \\
& \dot{E}_{D, \text { Exp }}=\dot{m}_{\text {ref }}\left(e_{f, \text { Exp,In }}-e_{f, \text { Exp }, \text { Out }}\right) .
\end{aligned}
$$

The exergy defect $\left(\delta_{i}\right)$, specific exergy defect $\left(\varphi_{i}\right)$ and exergy efficiency $\left(\eta_{E x}\right)$ are shown as follows from Eq. 9 -11 ,

$$
\begin{aligned}
& \delta_{i}=\frac{E_{D, i}}{\sum E_{I n}}, \\
& \varphi_{i}=\frac{E_{D, i}}{Q_{\text {Evap }}}, \\
& \eta_{\text {Ex }}=\operatorname{COP}\left(\frac{T_{0}}{T_{\text {Evap }}}-1\right) .
\end{aligned}
$$

\section{Results and analysis}

\subsection{Optimum charge}

The optimum charge for this system needs to be determined by evaluating its $C O P$ at different charge amounts. Since the system is designed for $2.0 \mathrm{~kW}$, the respective COPs from $0.74 \mathrm{~kg}$ to $0.90 \mathrm{~kg}$ are shown in Fig. 2 . The output cooling capacity of $2.0 \mathrm{~kW}$ is dependent on the mass flow rate of the chilled water $\dot{m}_{C H}$, the specific heat capacity of water $c_{p}$ and the temperature difference between the inlet and outlet of the evaporator in the water side $\left(T_{C H, I n}-T_{C H, O u t}\right)$ as seen in the numerator of Eq. 2. The mass flow rate of chilled water is kept constant. Thus the temperature difference between the inlet and outlet of evaporator in the chilled water side should also be kept constant in order to produce the required cooling load of 
$2.0 \mathrm{~kW}$. The inlet chilled water temperature can be maintained at around $20^{\circ} \mathrm{C}$ since it is the supply condition from the chilled water bath, whilst the outlet temperature depends on the cooling effect achieved across the evaporator. When there is an increased amount of total refrigerant charge within the circuit, if the mass flow rate of the refrigerant is not reduced, the cooling effect would increase above $2.0 \mathrm{~kW}$. Thus to maintain a constant cooling capacity, the mass flow rate across the evaporator is reduced by throttling the refrigerant flow at the expansion valve. Typically, the mass flow rate is only reduced to an amount which allows the superheat value to be maintained between $4-5{ }^{\circ} \mathrm{C}$. The superheat is the difference between outlet evaporator refrigerant temperature and the saturation temperature calculated at the evaporator outlet pressure. This value has been chosen in order to prevent the damage of the compressors from liquid refrigerant entering it. The superheat value ensures that the refrigerant which leaves the evaporator and enters the compressor is in the superheated vapor region and the chances of liquid being present is very low.

The dome like behavior in Fig. 2 indicates that the charge of $0.84 \mathrm{~kg}$ of $\mathrm{R} 410 \mathrm{a}$ provides the optimum behavior or highest COP for the current system. Thus 0.84 $\mathrm{kg}$ is determined to be the optimum charge amount. In the case of overcharging the system, the COP drops rapidly, whilst when undercharged, the drop is not significant till it differs by more than $0.1 \mathrm{~kg}$. This suggests that care must be taken not to increase the overall charge of a system in the hopes of expecting improved performance and that as long as the refrigerant levels do not drop largely from the optimum, an adequate performance can be obtained.

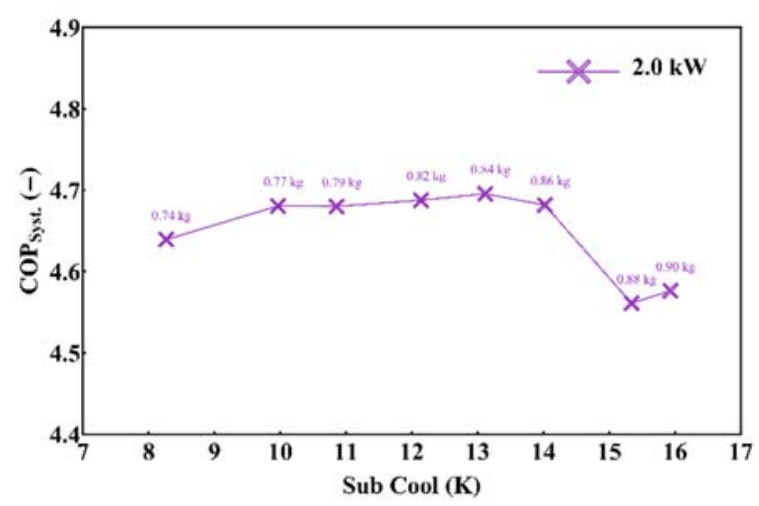

Fig. 2: The COP for the designed capacity of $2.0 \mathrm{~kW}$ at varied R410a charge amounts.

\subsection{Exergy destruction at $2.0 \mathrm{~kW}$}

As seen in Fig. 3, the exergy destruction rate is lowest for the newly determined optimum charge of $0.84 \mathrm{~kg}$. This reinforces the previous result. To further explore the reasons for the reducing exergy destruction when the optimum charge is reached and the increase when it is overcharged or undercharged, the component level exergy destruction will be investigated in the next section.

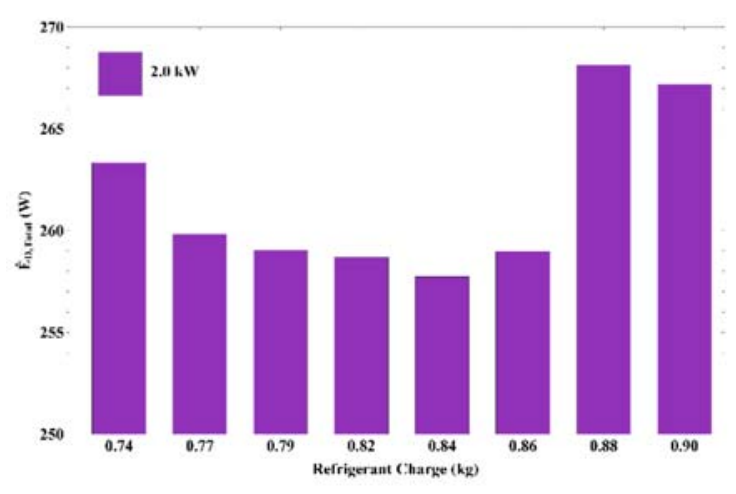

Fig. 3: The exergy destruction rate at $2.0 \mathrm{~kW}$ for varied R410a charge amounts

\subsection{Component exergy destruction at $2.0 \mathrm{~kW}$}

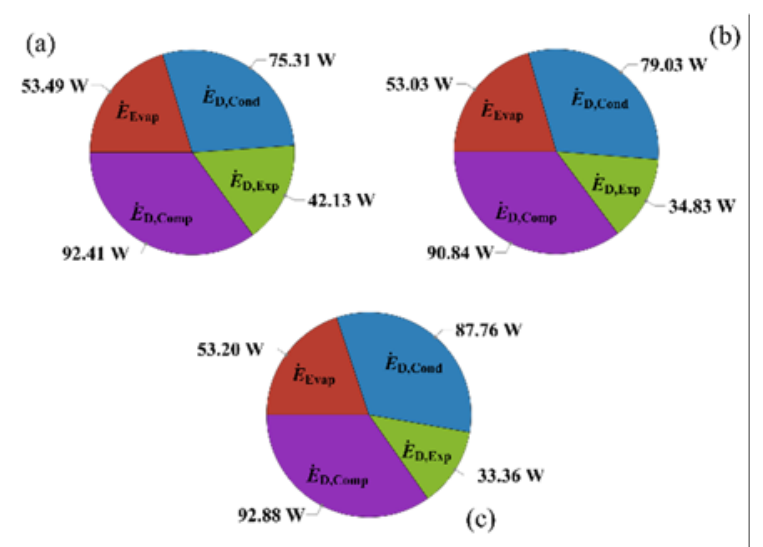

Fig. 4: The component exergy destruction at $2.0 \mathrm{~kW}$ for (a) $0.74 \mathrm{~kg}$, (b) $0.84 \mathrm{~kg}$ and (c) $0.90 \mathrm{~kg}$.

To compare the exergy destruction behavior for the design load of $2.0 \mathrm{~kW}$, the lowest, optimum and largest charge amounts of R410a are analyzed and presented in Fig. 4. It is possible to see that the exergy destruction within the condenser increases as the charge amount is increased. This could be caused by the reduced contact surface area within the heat exchangers since more liquid would accumulate at the end and the resistance to flow caused by this, which is indicated by the increased subcool temperatures in Fig. 2 as well. There is also a higher pressure in the condenser as the charge amount is increased and the pressure lift across the compressor is widened. This also results in an increased condenser temperature which all contribute towards the positive trend in exergy destruction.

The expansion valve shows the opposite trend with reduced exergy destruction rates. This could be a result of the reduced mass flow rates in order to maintain the constant cooling load. The evaporator shows the smallest exergy destruction during the optimum charge conditions. This is possibly due to the fact that the evaporator is working at its designed conditions and is exchanging maximum amount of heat per refrigerant $\mathrm{kg}$, undercharging requires more mass flow across the evaporator to achieve the required cooling whilst 
overcharging can result in inadequate vaporization. As for the compressor the high exergy destruction at both under and overcharge conditions could be a result of inadequate refrigerant amount or the reduced compressor performance at very low frequencies, respectively and the increased discharge pressures seen when the charge amount is increased. It is noted that the compressor is the largest contributor to the exergy destruction in all cases. As it is evident from the current work that the exergy destruction within the compressor contributes greatly to the overall system exergy destruction, it is evident that any improvements to the compressor would help mitigate these effects. The immediate achievable step would be to ensure that the pressure lift across the compressor is maintained at a relatively low value, such that the power consumption of the compressor can be reduced. To achieve lower pressure lifts, it would sometimes be necessary to have a larger capacity condenser or possibly increase the flow rates of water or air to provide better heat transfer. It might also be helpful to further improve the insulation for the compressor inlet such that the superheated vapor remains in its single phase and doesn't condense, the potential use of improved lubricants which are paired specifically for different types of refrigerants could help reduce the friction losses within the compressor and the exploration of special nano-fluids as lubricants are also being actively explored for improving compressor performance.

\subsection{Exergy defect at $2.0 \mathrm{~kW}$}

To further investigate the effect of the compressor on the exergy destruction of each individual component, the exergy defect is calculated according to Eq. 9. This provides the ratio between the exergy destroyed within a component and the exergy input into the system. The exergy input into the system is equal to work done by the compressor which is its electrical power consumption. Hence, the exergy defect provides a direct representation of the compressor's influence on the component level exergy destruction for this MVC chiller (see Fig. 5). The compressor shows very little avail with respect to the exergy defect as expected. However, the expansion device responds well to the reduced power input to the compressor and shows an adequate drop in its exergy destroyed, mainly attributed to reduced mass flow rates as per the previous section. The evaporator shows little improvement as well, since its conditions are not directly dependent on the compressor performance. The condenser however, shows an increase in exergy defect. This signals that the exergy destruction rate increase in the condenser due to increased sub cool, increased condenser temperature and increased pressure, which cumulatively is larger than the reduced exergy destruction rate in the compressor at lower powers. Thus adding excess refrigerant does not benefit the system and would only increase its total exergy destruction by reducing the performance of the condenser and maintaining almost a similar level of exergy destruction within the compressor.

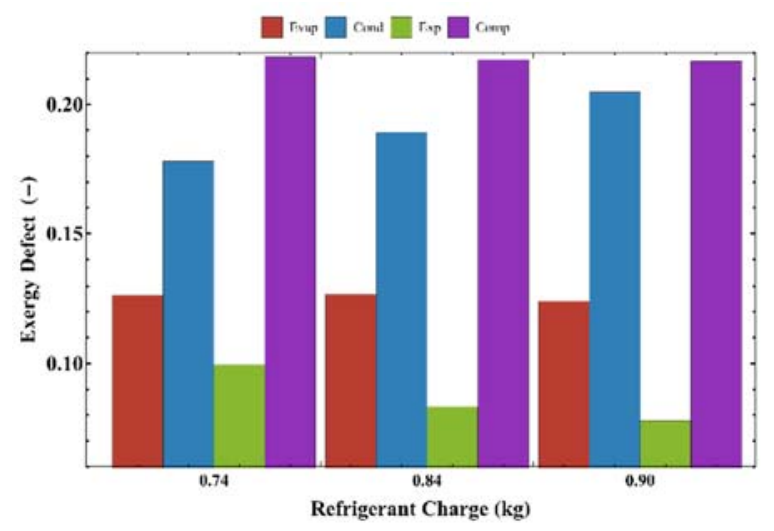

Fig. 5: The exergy defect at $2.0 \mathrm{~kW}$ for $0.74 \mathrm{~kg}, 0.84 \mathrm{~kg}$ and $0.90 \mathrm{~kg}$ of R410a.

\subsection{Specific exergy destruction at $2.0 \mathrm{~kW}$}

Since the chiller is being analyzed in the cooling mode, the specific exergy defect can also be evaluated according to Eq. 10 with respect to the cooling load. Fig. 6 shows the specific exergy defect with respect to the cooling capacity. In this case, the cooling capacity is maintained at $2.0 \mathrm{~kW}$ which is the designed load for this chiller. This provides the interesting observation for the three components of evaporator, expansion device and compressor, which all show the least exergy destruction at the optimum charge of $0.84 \mathrm{~kg}$, whilst exhibiting increased exergy destruction rates at all other charge amounts. The condenser on the other hand behaves in a similar manner to that of exergy defect shown in Fig. 5, with an increasing exergy destruction at larger charge amounts. This suggests that even though the load to the condenser doesn't increase with increased refrigerant charge amount, the restrictions in mass flow rate resulted in the increased condenser temperature and pressure at overcharged conditions, which had a direct impact on the condenser behavior. This scenario should be avoided, in order to maintain the performance of the condenser.

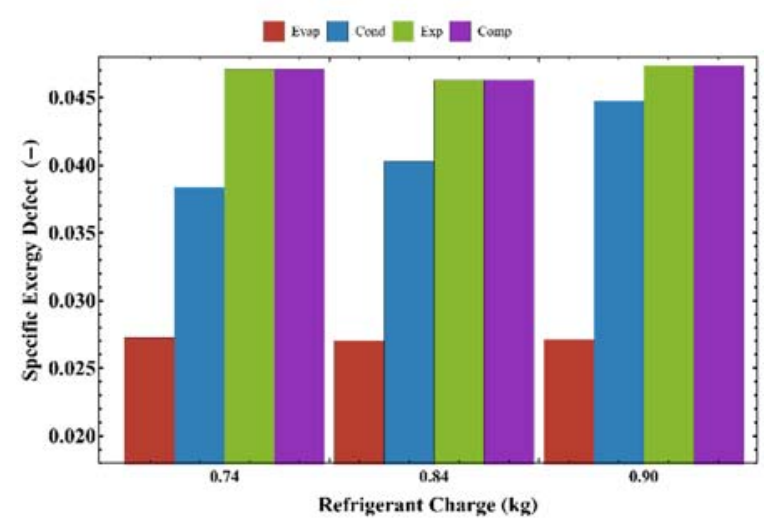

Fig. 6: Specific exergy destruction at $2.0 \mathrm{~kW}$ for $0.74 \mathrm{~kg}$, $0.84 \mathrm{~kg}$ and $0.90 \mathrm{~kg}$

\subsection{Exergy Efficiency at $2.0 \mathrm{~kW}$}




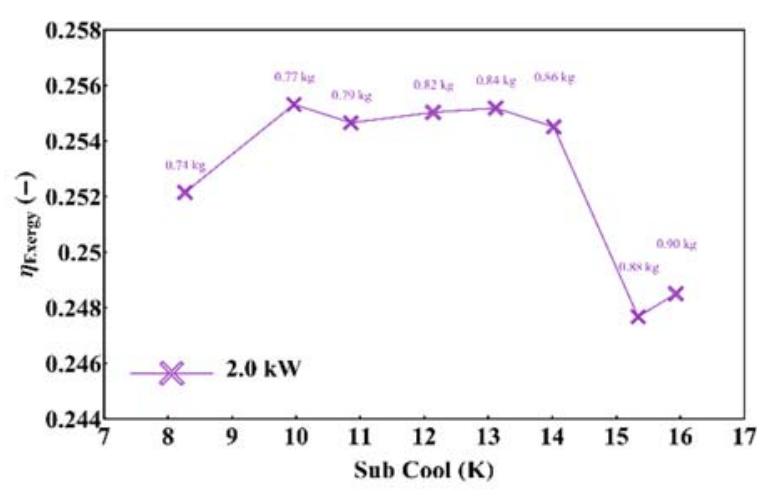

Fig. 7: The exergy efficiency at $2.0 \mathrm{~kW}$ for varied charge amounts.

The exergy efficiency (see Fig. 7) represents the irreversibilities or exergy destruction and its effects on the overall refrigeration cycle. It is clearly seen that the evaporator and compressor have the largest effect on this since Eq. 11 shows its dependence on COP which itself is a function of the cooling effect at the evaporator and the compressor power input. It is expected that the optimum charge should also exhibit the optimum exergetic efficiency. However, the slight variations in the evaporator temperature shown in Fig. 8, result in the shifting of the exergy efficiency towards a more positive value as is the case of $0.77 \mathrm{~kg}$.

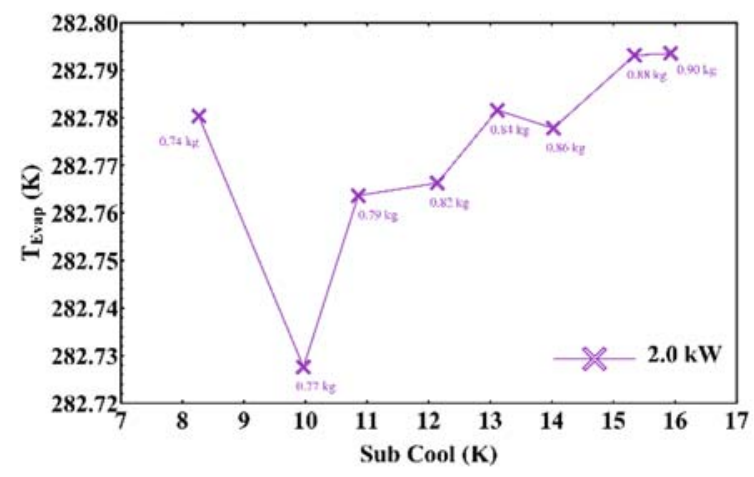

Fig. 8: The evaporator temperature at $2.0 \mathrm{~kW}$ for varied charge amounts.

The spike in exergy efficiency at $0.77 \mathrm{~kg}$ seen in Fig. 7 occurs as the evaporator temperature cools further away from the dead state temperature. It is hence more beneficial when there is a lower evaporator temperature in terms of the exergy efficiency. This however, comes at the cost of potentially lowering the COP due to the larger compressor power required to produce a larger cooling effect for a constant charge, often signified by a larger pressure lift as well. Focusing on the optimum charge amount of $0.84 \mathrm{~kg}$ in Fig. 7 , it takes the $2^{\text {nd }}$ highest exergetic efficiency and follows the peak like behavior when the value at $0.77 \mathrm{~kg}$ is ignored, signifying its high
$C O P$, low exergy destruction and reiterates its selection as the optimum charge.

\section{Conclusions}

The analysis of a $2.0 \mathrm{~kW}$ chiller, has allowed the determination of the optimum amount of charge of R410a as $0.84 \mathrm{~kg}$ and also allowed the exploration of the exergetic parameters. The exergy destruction exhibited that the compressor was the largest contributor to the irreversibilities within the system and that the total exergy destruction was the lowest at $0.84 \mathrm{~kg}$. Over charging or under charging refrigerant will cause increased losses and contribute to the lower efficiency of each component. The exergy defect and specific exergy defect highlighted the dependency of each component on the exergy destruction by the compressor and also the cooling load of $2.0 \mathrm{~kW}$. The condenser was the only component which showed increasing exergy destruction with increased charge amount for both of these parameters. Finally, the exergetic efficiency showed the resultant exergy destructions and their effects on the overall performance of the chiller system with the COP contributing largely to the final value, whilst any decrease in evaporator temperature from the dead state temperature can cause positive exergetic efficiencies even at low COPs.

\section{Acknowledgements}

The authors are grateful to the funding provided by the Kyushu University Green Asia program for the doctoral funding of Uthpala Perera and to the collaborative effort on the experiments by Mr. K. Takezato and Mr. S. Senba.

$\begin{array}{ll}\text { AHRI } & \begin{array}{l}\text { air conditioning, heating and } \\ \text { refrigeration institute } \\ C\end{array} \\ \text { specific heat capacity }\left(\mathrm{kJ} \mathrm{kg}^{-1} \mathrm{~K}^{-1}\right) \\ \text { coefficient of performance }(-) \\ G W P & \text { global warming potential } \\ h & \text { enthalpy }\left(\mathrm{kJ} \mathrm{kg}^{-1}\right) \\ I E A & \text { international energy agency } \\ M V C & \text { mechanical vapor compression } \\ \text { ODP } & \text { ozone depletion potential } \\ P & \text { power }(\mathrm{kW}) \\ p & \text { pressure }\left(\mathrm{kPa}^{2}\right) \\ Q & \text { heat transfer rate }(\mathrm{W}) \\ S & \text { entropy }\left(\mathrm{kJ} \mathrm{kg} \mathrm{K}^{-1}\right) \\ T & \text { temperature }(\mathrm{K})\end{array}$

\section{Nomenclature}

air conditioning, heating and refrigeration institute

coefficient of performance (-)

global warming potential ,

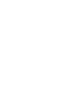




$\begin{array}{ll}t & \text { time }(\mathrm{s}) \\ V & \text { volume }\left(\mathrm{m}^{3}\right) \\ W & \text { work }(\mathrm{W}) \\ \dot{m} & \text { mass flow rate }\left(\mathrm{kg} \mathrm{s}^{-1}\right) \\ T_{0} & \text { dead state temperature }(\mathrm{K}) \\ P_{0} & \text { dead state pressure }(\mathrm{kPa}) \\ \dot{E}_{D} & \text { exergy destruction rate }(\mathrm{W}) \\ e_{f} & \text { flow exergy rate }(\mathrm{W}) \\ h_{0} & \text { dead state enthalpy }\left(\mathrm{kJ} \mathrm{kg}^{-1}\right) \\ s_{0} & \text { dead state entropy }\left(\mathrm{kJ} \mathrm{kg}^{-1} \mathrm{~K}^{-1}\right)\end{array}$

Greek symbols

$\begin{array}{ll}\delta & \text { exergy defect (-) } \\ \varphi & \text { specific exergy defect (-) } \\ \eta & \text { exergy efficiency (-) }\end{array}$

Subscripts

$\mathrm{CH}$

chilled water

$C W$

cooling water

Comp

compressor

Cond

condenser

CV

control volume

Evap

evaporator

Ex

exergy

Exp

expansion valve

In

inlet

Out

outlet

\section{References}

1) A. Vaughan, "Warming climate to nearly double demand for cooling appliances," Guard., (2018). https://www.theguardian.com/environment/2018/apr /17/demand-for-cooling-predicted-to-outstripheating-as-earth-warms (accessed November 23, 2020).

2) P. Lester, "History of air conditioning," Dep. Energy, (2015). https://www.energy.gov/articles/history-airconditioning (accessed October 26, 2019).

3) "The Future of Cooling," IEA, Paris, 2018. doi:10.1787/9789264301993-en.

4) B.J. van Ruijven, E. De Cian, and I. Sue Wing, "Amplification of future energy demand growth due to climate change," Nat. Commun., 10 (1) 1-12 (2019). doi:10.1038/s41467-019-10399-3.
5) M.H. Mahmood, M. Sultan, and T. Miyazaki, "Study on water-vapor adsorption onto polymer and carbon based adsorbents for air-conditioning applications," Evergreen, $6 \quad$ (3) 215-224 (2019). doi:10.5109/2349297.

6) M.H. Mahmood, M. Sultan, T. Miyazaki, and S. Koyama, "Desiccant air-conditioning system for storage of fruits and vegetables: pakistan preview," Evergreen, 3 (1) 12-17 (2016). doi:10.5109/1657381.

7) I. Yaningsih, M.H. Mahmood, A.T. Wijayanta, T. Miyazaki, and S. Koyama, "Experimental study on dehumidification technology using honeycomb desiccant block," Evergreen, 5 (2) 11-18 (2018). doi:10.5109/1936212.

8) P. Byrne, N. Putra, T. Maré, N. Abdallah, P. Lalanne, I. Alhamid, P. Estelle, A. Yatim, and A.L. Tiffonnet, "Design of a solar ac system including a pcm storage for sustainable resorts in tropical region," Evergreen, 6 (2) 143-148 (2019). doi:10.5109/2321009.

9) S.M. Ali, and A. Chakraborty, "Performance study of adsorption cooling cycle for automotive airconditioning," Evergreen, 2 (1) 12-22 (2015). doi: $10.5109 / 1500423$.

10) J. Ko, N. Takata, K. Thu, and T. Miyazaki, "Dynamic modeling and validation of a carbon dioxide heat pump system," Evergreen, 7 (2) 172-194 (2020). doi:10.5109/4055215.

11) J.M. Calm, and P.A. Domanski, "R22 replacement status," EcoLibrium, 3 (10) 18-24 (2004).

12) B. Gschrey, J. Kleinschmidt, and S. Barrault, "Briefing Paper: HFCs and HFC alternatives in split air conditioning systems," 2020. https://www.oekorecherche.de/sites/default/files/pub likationen/briefing_paper_hfc_alternatives_en.pdf.

13) "Fluorinated greenhouse gases 2019," Copenhagen, 2019. doi:10.2800/477426.

14) T. Hirao, H. Mizuno, K. Ueda, M. Kai, and H. Yamada, "Efforts to reduce greenhouse gas emissions for air conditioning and refrigeration products," Mitsubishi Heavy Ind. Tech. Rev., 55 (1) 38-48 (2018). http://www.mhi.co.jp/technology/review/pdf/e551/e 551038.pdf.

15) T. Okada, "Refrigerant Conversion Activities Including Energy Efficiency in Japan," in: 41 st OpenEnded Work. Gr., JRAIA, Bangkok, 2019: pp. 1-23.

16) B. Maranion, M. Pizano, and A. Woodcok, "Montreal Protocol On Substances That Deplete The Ozone Layer: Report Of The Technology And Economic Assessment Panel," Kenya, 2020.

17) M. Seki, "The latest developments under the Montreal Protocol and the Kigali Amendment," 2017.

18) "Handbook for the Montreal Protocol on Substances that Deplete the Ozone Layer," Nairobi, 2019.

19) "The Kigali Amendment: The amendment to the Montreal Protocol agreed by the Twenty-Eighth Meeting of the Parties," 2016. https://ozone.unep.org/en/handbook-montreal- 
protocol-substances-deplete-ozone-layer/41453 (accessed March 17, 2019).

20) "Revised F-Gas Law in Japan," Government of Japan, 2015. http://www.env.go.jp/earth/ozone/hiyasuwaza/eng/revised_f-gas_law_in_japan.html (accessed March 16, 2019).

21) "EU legislation to control f-gases," Eur. Comm., (2015). https://ec.europa.eu/clima/policies/fgas/legislation_en (accessed March 16, 2019).

22) S. Fukuda, H. Kojima, C. Kondou, N. Takata, and S. Koyama, "Experimental assessment on performance of a heat pump cycle using r32/r1234yf and r744/r32/r1234yf," Int. Refrig. Air Cond. Conf., 1651 (2016). http://docs.lib.purdue.edu/iracc/1651.

23) S. Fukuda, C. Kondou, N. Takata, and S. Koyama, "Low gwp refrigerants r1234ze(e) and r1234ze(z) for high temperature heat pumps," Int. J. Refrig., 40 161173 (2014). doi:10.1016/j.ijrefrig.2013.10.014.

24) K. Thu, K. Takezato, N. Takata, T. Miyazaki, and Y. Higashi, "Performance evaluation of a heat pump system using an hfc32/hfo1234yf blend with gwp below 150 for heating applications," Appl. Therm. Eng., $\quad \mathbf{1 8 2} \quad 115952 \quad$ (2021). doi:10.1016/j.applthermaleng.2020.115952.

25) W. Chen, "A comparative study on the performance and environmental characteristics of r410a and r22 residential air conditioners," Appl. Therm. Eng., 28 (1) 1-7 (2008). doi:10.1016/J.APPLTHERMALENG.2007.07.018.

26) S. Fukuda, H. Kojima, C. Kondou, N. Takata, and S. Koyama, "Comparative assessment on irreversible losses in heat pumps using r744/r32/r1234yf and r744/r32/r1234ze(e)," Sci. Technol. Built Environ., 22 (8) 1118-1127 (2016). doi:10.1080/23744731.2016.1206452.

27) C.U.A. Perera, N. Takata, T. Miyazaki, Y. Higashi, B.B. Saha, and K. Thu, "Exergy investigation of $\mathrm{r} 410 \mathrm{a}$ as a 'drop in' refrigerant in a water-cooled mechanical vapor compression cycle," Heat Transf. Eng., $\quad 7632 \quad 1-18 \quad$ (2020). doi:10.1080/01457632.2020.1776990.

28) A. Wahid, D.R. Mustafida, and Y.A. Husnil, "Exergy analysis of coal-fired power plants in ultra supercritical technology versus integrated gasification combined cycle," Evergreen, 7 (1) 32-42 (2020). doi:10.5109/2740939.

29) R. Ben Jemaa, R. Mansouri, I. Boukholda, and A. Bellagi, "Energy and exergy investigation of r1234ze as r134a replacement in vapor compression chillers," Int. J. Hydrogen Energy, 42 (17) 12877-12887 (2017). doi:10.1016/j.ijhydene.2016.12.010.

30) R. Yumrutaş, M. Kunduz, and M. Kanoğlu, "Exergy analysis of vapor compression refrigeration systems," Exergy, An Int. J., 2 (4) 266-272 (2002). doi:10.1016/S1164-0235(02)00079-1.

31) H. Cho, and C. Park, "Experimental investigation of performance and exergy analysis of automotive air conditioning systems using refrigerant r1234yf at various compressor speeds," Appl. Therm. Eng., 101 30-37 doi:10.1016/J.APPLTHERMALENG.2016.01.153.

32) T. Morosuk, and G. Tsatsaronis, "Advanced exergetic evaluation of refrigeration machines using different working fluids," Energy, 34 (12) 2248-2258 (2009). doi:10.1016/j.energy.2009.01.006.

33) E. Bilgen, and H. Takahashi, "Exergy analysis and experimental study of heat pump systems," Exergy, An Int. J., 2 (4) 259-265 (2002). doi:10.1016/S11640235(02)00083-3.

34) M.I. Alhamid, N. Nasruddin, Budihardjo, E. Susanto, T.F. Vickary, and M. Arif Budiyanto, "Refrigeration cycle exergy-based analysis of hydrocarbon (r600a) refrigerant for optimization of household refrigerator," Evergreen, 6 (1) 71-77 (2019). doi:10.5109/2321015.

35) E.W. Lemmon, I.H. Bell, M.L. Huber, and M.O. McLinden, "NIST standard reference database 23: reference fluid thermodynamic and transport properties-refprop, version 10.0," Natl. Inst. Stand. Technol. Stand. Ref. Data Program, Gaithersbg., (2018). doi:10.18434/T4JS3C.

36) "Mathematica, version 10.3," (2015). https://www.wolfram.com/mathematica/.

37) C. Uthpala, A. Perera, B.B. Saha, T. Miyazaki, S. Koyama, and K. Thu, "Exergy analysis of a vapour compression chiller at elevated chilled water outlet conditions," Eng. Sci. Reports, Kyushu Univ., 39 (2) 7-13 (2018). 